\title{
Psychopharmacological Treatment for Posttraumatic Stress Disorders in Naval Military Subjects
}

\author{
Anderson Diaz-Perez ${ }^{1,2}$, Elvis Eliana Pinto Aragón ${ }^{3}$, Carmenza Leonor Mendoza Cataño ${ }^{3}$, \\ Moraima del Toro Rubio ${ }^{2}$ \& Elkin Navarro-Quiroz ${ }^{4}$ \\ ${ }^{1}$ School of Basic and Biomedical Sciences, Universidad Simón Bolívar, Barranquilla; Faculty of Health Sciences, \\ Corporación Universitaria Rafael Núñez, Cartagena de Indias. Universidad Popular del Cesar, Valledupar, \\ Colombia \\ ${ }^{2}$ Faculty of Health Sciences, Corporación Universitaria Rafael Núñez, Cartagena de Indias, Universidad Popular \\ del Cesar, Valledupar, Colombia \\ ${ }^{3}$ Faculty of Social and Human Sciences, Universidad de la Guajira, Colombia \\ ${ }^{4}$ School of Basic and Biomedical Sciences, Universidad Simón Bolívar, Barranquilla, Colombia \\ Correspondence: Anderson Diaz-Perez, School of Basic and Biomedical Sciences, Universidad Simón Bolívar, \\ Barranquilla, Colombia. E-mail: ander2711@gmail.com
}

Received: December 14, 2017 Accepted: January 17, 2018 Online Published: January 17, 2018

doi:10.5539/gjhs.v10n3p33 URL: https://doi.org/10.5539/gjhs.v10n3p33

\begin{abstract}
Introduction: Posttraumatic Stress Disorder (PTSD) is a psychiatric syndrome known since 1980 with multiple names in the military field. Its etiology is multicausal, whose predominant factor is the lack of adaptation and managing with events considered traumatic. Objective: To describe the clinical characteristics such as the type of psychological and pharmacological treatment received by the naval military with diagnosis of Posttraumatic Stress Disorder at the Psychiatric Unit of Cartagena's Naval Hospital.

Methodology: A descriptive, retrospective cross-sectional study with an associative approach (Crosstabulation). The sample was 242 navy subjects with PTSD diagnosis. The information was collected with a data collection form of medical records. The information analysis was developed through the program SPSS ${ }^{\circledR} 21.0$. Chi ${ }^{2}$ and value of $\mathrm{p} \leq 0.05$ calculation was applied through the crossing of variables.
\end{abstract}

Results: The most prevalent type of traumatic event was the one represented by combat with the presence of depressive disorders and anxiety with a value of $\mathrm{p} \leq 0.05$.

Conclusions: The PTSD severity is related to the severity of the event, in addition if the trumatic event was repetitive.

Keywords: PTSD, posttraumatic stress, epidemiology, comorbidity (psychiatry), war, military, Colombia, stress, trauma, disorder, psychiatry, DeSc

\section{Introduction}

Post-traumatic stress since 1980 has been known for a wide variety of names that respond to different psychiatric syndromes, including neurosis by combat traumatism (Friedman, Schnurr, \& McDonagh-Coyle, 1994, p. 1), it has even been associated with Burnout Syndrome "fatigue by confrontation". Nowadays it is now known that there is no single predisposing effect neither manifestations or unique psychological and social consequences, concerning the way military personnel treat Post-Traumatic Stress Disorder (PTSD), which face war violent situations, as well, for the mistreatment of his superiors, even of his companions (Castaño \& Rosado, 2015, p. 37).

Posttraumatic Stress Disorder PTSD is well defined and linked to both psychological and social suffering and dysfunction. It is associated with the way military subjects confront the adverse factors considered as stressful and traumatic, which means, that the PTSD has a direct relation with people personality characteristics (Corzo \& Bohórquez, 2009, p. 15). Thus, its etiology is conditioned to the psychological and organic adaptation of the person who suffers it, even considering the existence of genetic predisposition, coupled with conditions such as traumas suffered during childhood, cultural, economic and social aspects that contribute to consider certain phenomena as traumatic actions and therefore to (PTSD) manifestation, reasons which makes it to be considered as a 
multifactorial disease (Friedman et al., 1994; Castaño \& Rosado, 2015; Corzo \& Bohórquez, 2009; Stein, Jang, Taylor, Vernon, \& Livesley, 2002). In 1987, the prevalence of post-traumatic stress disorder was between $0.5 \%$ and $10.8 \%$ for men and between $1.3 \%$ and $18.3 \%$ for women with a global prevalence of $16.66 \%$, lower than the values reported in Vietnam veterans who was between 20\% and 33\% (Corzo \& Bohórquez, 2009, p. 15). Some studies associate PTSD with other types of disorders such as food disorder, especially in veterans (Mitchell, Porter, Boyko, \& Field, 2016), No previous and updated studies about PTSD incidence or prevalence were found, nor studies that show the onset and duration of the disease, however, it is believed that the combination of depression prevalence with PTSD is around 20\% among active military personnel, and 30\% among veterans (Fink et al., 2016).

The studies carried out in Colombia concerning PTSD in military personnel and public forces subjects, describe that according to the type of trauma psychological and psychopharmacological intervention also varies, where trauma can be classified according to the type of military exercise as its sequelae at short, medium and long term, because the managing strategies by the military subject are different according to the training received (Corzo \& Bohórquez, 2009; Friedman et al., 1994; Loaiza \& Posada, 2016; Suárez \& Peralta, 2016; Vallejo Samudio \& Terranova Zapata, 2009).

The objective is to describe the clinical characteristics associated with the type of treatment received by the navy subjects with diagnosis of Posttraumatic Stress Disorder treated at the Navy Hospital Psychiatry Unit.

\section{Methodology}

Type of study, descriptive, retrospective cross-sectional with an associative approach (Crosstabulation). The population was constituted by 650 military personnel diagnosed with PTSD treated at the Navy Hospital Psychiatric Unit from Cartagena de Indias city during the years 2012 to 2014. The sample of 242 military personnel, calculated with a confidence level of $95 \%$ and $0.05 \%$ error.

Data were taken from clinical profiles that included both socio-demographic variables such as: age, marital status, level of education, risk behaviors, as well as variables that identify patient's clinical comorbidity: traumas during childhood, clinical and psychological behaviors, among others. Data analysis was done with the program SPSS ${ }^{\circledR}$ 21.0. The associative approach (Crosstabulation) applying the $\mathrm{Chi}^{2}$ with a value of $\mathrm{p} \leq 0.05$.

\section{Results}

It is observed that $75 \%$ of naval personnel were between the ages of 18 and 29 , with the majority of the population at the age of 20 at the moment of being diagnosed with Posttraumatic Stress Disorder PTSD. (Graph 1)

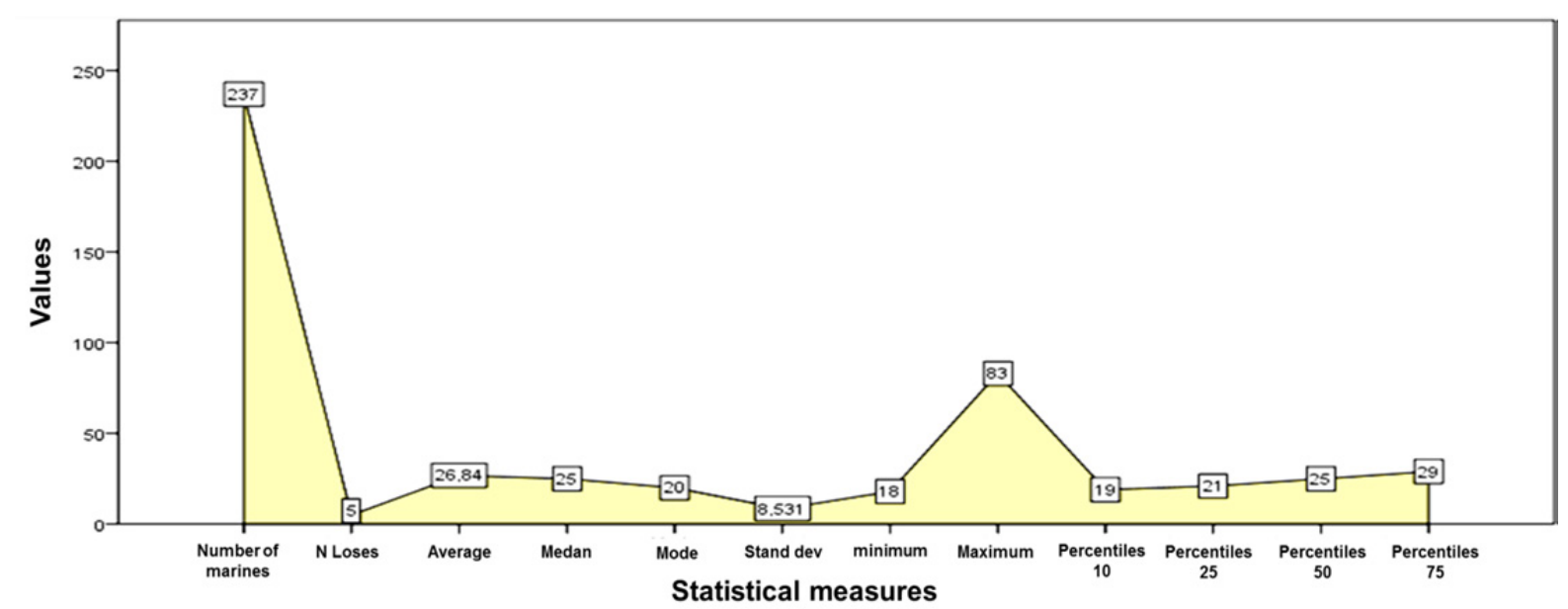

Graph 1. Statistical data of age at diagnosis moment

Graph 2 - (2a). When correlating the age at the time of the diagnosis of the disorder with the number of combats and the number of hospitalizations, it was found that it is not necessary to have a great number of combats, even the PTSD was presented in navy subjects that had never been exposed to battles, which it could mean that the disorder is due to other types of events such as mistreatment or aggression (See Table 3). It is observed that when the subject had participated in a greater the number of combat decreases the possibility of early diagnosis of the disorder. 
Graph 2 - (2b), describes average number of hospitalizations that navy subject can have even before being diagnosed, which is in an average 1 to 3 hospitalizations and that the most susceptible ones are naval personnel under 29 years.
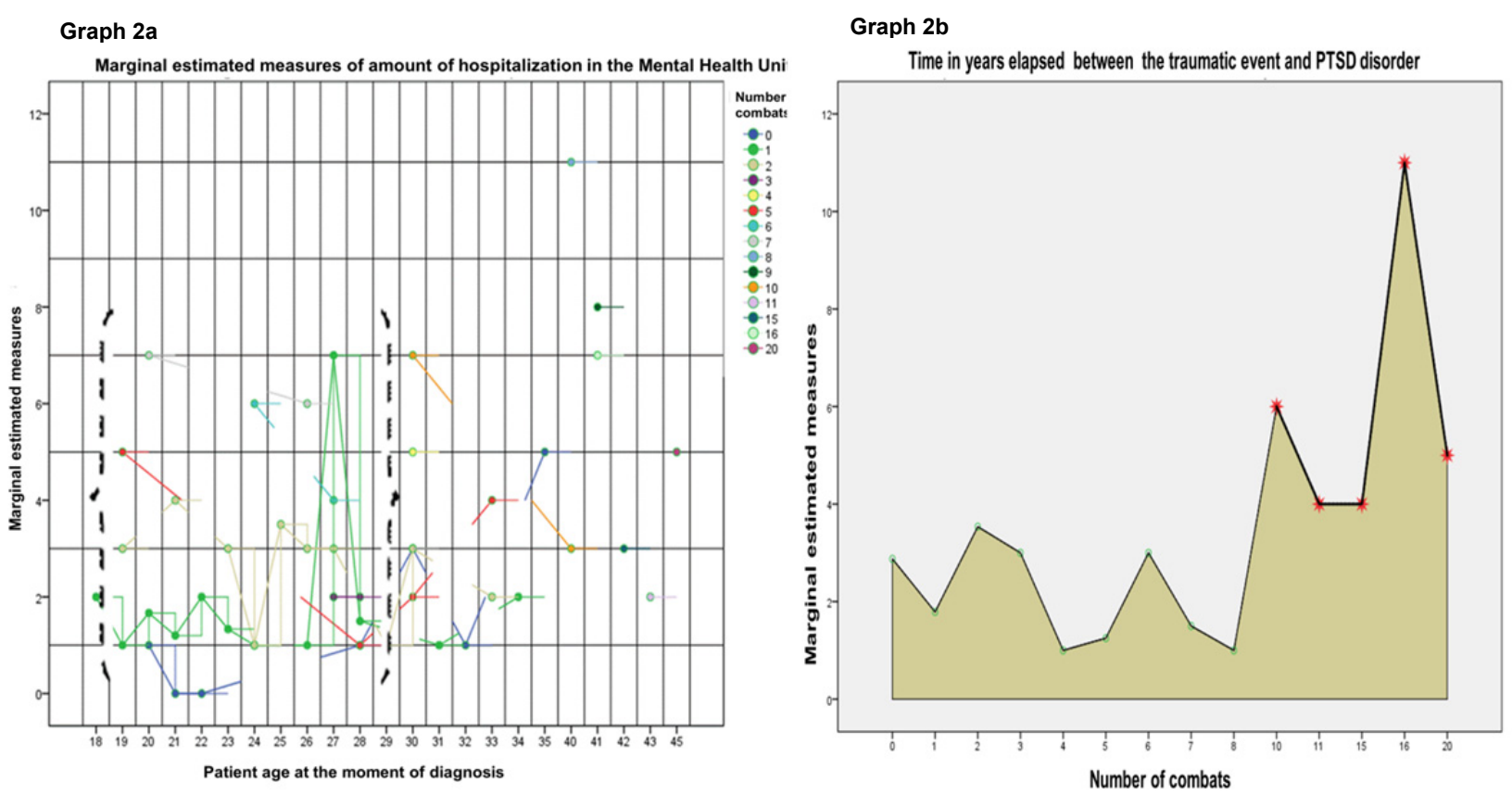

Graph 2. Correlation between age at the time of diagnosis (PTSD) with the number of combats and hospitalizations and the time elapsed between the traumatic event and the disorder

The navy personnel diagnosed with PTSD, $64.5 \%$ come from of urban areas, $79.3 \%$ from catholic families and $41.7 \%$ were single at the moment of disorder diagnosis. $56.2 \%$ of the patients report childhood traumas because child abuse. (Table 1)

There was no association between schooling level with military rank of navy personnel diagnosed with PTSD with a p value of $\geq 0.05$. However, in $62.4 \%$ of cases patients have a high school academic level with the rank of marine, followed by $10.3 \%$ having the same rank that the previous group but with at a technician or technologist degree (Table 2).

Concerning the type of patient, hospitalized or outpatient, no statistical association was found with the type of psychoactive substance consumed by patients diagnosed with PTSD with a $p$ value of $\geq 0.05$. As for the most consumed substances, it was found that alcohol was the most consumed, $14 \%$ in outpatients and $23.1 \%$ in hospitalized patients. (See Table 2) 
Table 1. Sociodemographic characteristics of Marines diagnosed with PTSD

\begin{tabular}{|c|c|c|c|c|c|c|c|}
\hline \multicolumn{2}{|l|}{$\begin{array}{l}\text { Civil status } \\
\text { n (\%) }\end{array}$} & \multicolumn{2}{|l|}{$\begin{array}{l}\text { Religion } \\
\text { N (\%) }\end{array}$} & \multicolumn{2}{|l|}{$\begin{array}{l}\text { Childhood trauma } \\
\text { n (\%) }\end{array}$} & \multicolumn{2}{|c|}{$\begin{array}{l}\text { Birth origin } \\
\text { n (\%) }\end{array}$} \\
\hline NDR & $2(0,8)$ & NDR & $5(2,1)$ & NDR & $95(39,3)$ & NDR & $5(2,1)$ \\
\hline Married & $53(21,9)$ & Atheist & $1(0,4)$ & Sexual abuse & $4(1,7)$ & Country & $81(33,5)$ \\
\hline Single & $101(41,7)$ & Catholic & $192(79,3)$ & Physical and Psychological mistreatment & $136(56,2)$ & Urban & $156(64,5)$ \\
\hline Free union & $84(34,7)$ & Christian & $36(14,9)$ & No & $7(2,9)$ & Total & $242(100)$ \\
\hline Widow & $2(0,8)$ & Evangelical & $8(3,3)$ & Total & $242(100)$ & & \\
\hline Total & $242(100)$ & Total & $242(100)$ & & & & \\
\hline
\end{tabular}

n: Marine diagnosed with PTSD. (\%) Percentage. NDR No data reported in the clinical profile.

It was found that a group of patients consume marijuana in isolation, $7.4 \%$ in the outpatients, and $4.5 \%$ in the hospitalized, as well a tendency to use other types of substances such as alcohol, cocaine, cigarette, among others. (See Table 2).

Table 2. Characteristics of marines diagnosed with (PTSD) according with military rank and psychoactive substances consumption

\begin{tabular}{|c|c|c|c|c|c|c|}
\hline & & \multicolumn{5}{|c|}{ Military Rank } \\
\hline & & $\begin{array}{l}\text { Professional } \\
\text { Marine }\end{array}$ & $\begin{array}{l}\text { Regular } \\
\text { Marine }\end{array}$ & $\begin{array}{l}\text { Petty } \\
\text { Officer }\end{array}$ & $\mathbf{J i}^{2}$ & $p$-value \\
\hline & & n (\%) & n (\%) & n (\%) & \multirow{6}{*}{12,981} & \multirow{6}{*}{0,112} \\
\hline \multirow{8}{*}{$\begin{array}{l}\text { Educational } \\
\text { level }\end{array}$} & NDR & $0(0,0)$ & $4(1,7)$ & $0(0,0)$ & & \\
\hline & Elementary school & $0(0,0)$ & $30(12,4)$ & $0(0,0)$ & & \\
\hline & High school & $15(6,2)$ & $151(62,4)$ & $1(0,4)$ & & \\
\hline & Technician/technologist & $3(1,2)$ & $25(10,3)$ & $2(0,8)$ & & \\
\hline & \multirow[t]{4}{*}{ University } & $0(0,0)$ & $11(4,5)$ & $0(0,0)$ & & \\
\hline & & \multicolumn{5}{|c|}{ Type of patient } \\
\hline & & \multirow{2}{*}{$\begin{array}{l}\text { NRDH } \\
\text { n (\%) }\end{array}$} & \multirow{2}{*}{$\begin{array}{l}\text { outpatient } \\
\text { n (\%) }\end{array}$} & \multirow{2}{*}{$\begin{array}{l}\text { Hospitalized } \\
\text { n (\%) }\end{array}$} & \multirow[t]{2}{*}{$\mathbf{J i}^{2}$} & $p$-value \\
\hline & & & & & & \multirow{11}{*}{0,161} \\
\hline \multirow{10}{*}{$\begin{array}{l}\text { Psychoactive } \\
\text { substances } \\
\text { consumption }\end{array}$} & NDR & $0(0,0)$ & $7(2,9)$ & $11(4,5)$ & \multirow{10}{*}{23,83} & \\
\hline & Alcohol & $1(0,4)$ & $34(14)$ & $56(23,1)$ & & \\
\hline & Alcohol + cigarette & $0(0,0)$ & $20(8,3)$ & $19(7,9)$ & & \\
\hline & $\begin{array}{l}\text { Alcohol }+ \text { cigarette }+ \text { Hallucinogenic } \\
\text { Substances }\end{array}$ & $0(0,0)$ & $1(0,4)$ & $1(0,4)$ & & \\
\hline & Alcohol + Hallucinogenic Substances & $2(0,8)$ & $7(2,9)$ & $6(2,5)$ & & \\
\hline & Cigarette & $2(0,8)$ & $17(7)$ & $17(7)$ & & \\
\hline & Cigarette + Hallucinogenic Substances & $0(0,0)$ & $2(0,8)$ & $1(0,4)$ & & \\
\hline & Cocaine & $0(0,0)$ & $1(0,4)$ & $2(0,8)$ & & \\
\hline & Cocaine + Marihuana & $0(0,0)$ & $1(0,4)$ & $5(2,1)$ & & \\
\hline & Marihuana & $0(0,0)$ & $18(7,4)$ & $11(4,5)$ & & \\
\hline
\end{tabular}

n: Marine diagnosed with PTSD. (\%) Percentage. NDR No data reported in the clinical profile. 
An associative approach was found between the type of event that possibly triggered PTSD with psychological disorders with a value of $\mathrm{p} \geq 0.05$. It was found the presence of depressive and/or Anxiety Disorder (ADD) with exposure to combat in $3.6 \%$, with the dismemberment of a partner or himself at $4.5 \%$, with the fact of having been exposed to physical or psychological mistreatment by a superior in $12.4 \%$, and torture and abduction in $2.9 \%$ related to adaptive disorder and / or anxiety. (See Table 3)

Table 3. Event or trauma that may possibly triggered PTSD with the type of Psychological Disorder manifested by the naval military

\section{Type of event that possibly triggered PTSD}

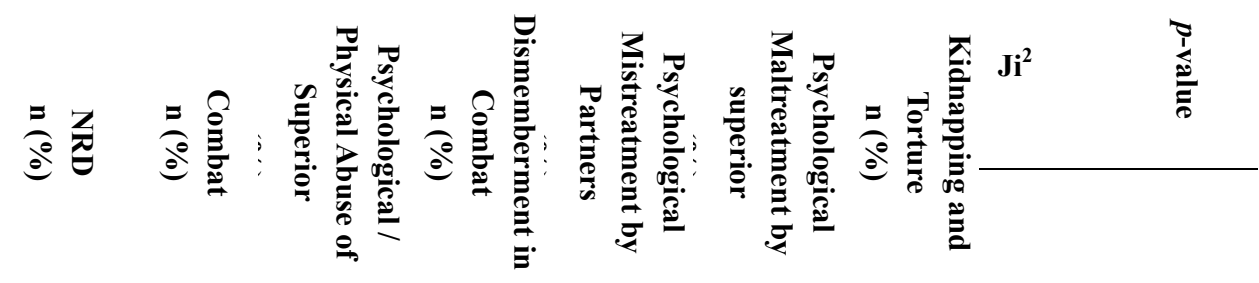

\begin{tabular}{|c|c|c|c|c|c|c|c|c|c|c|}
\hline \multirow{8}{*}{$\begin{array}{l}\text { Diagnosed } \\
\text { Psychological } \\
\text { Disorders }\end{array}$} & NRD & $2(0,8)$ & $16(6,6)$ & $0(0,0)$ & $9(3,7)$ & $6(2,5)$ & $12(5)$ & $0(0,0)$ & \multirow{8}{*}{74,927} & \multirow{8}{*}{0,001} \\
\hline & Schizophrenia & $0(0,0)$ & $0(0,0)$ & $0(0,0)$ & $2(0,8)$ & $0(0,0)$ & $0(0,0)$ & $0(0,0)$ & & \\
\hline & $\begin{array}{l}\text { Mental } \\
\text { retardation }\end{array}$ & $0(0,0)$ & $0(0,0)$ & $0(0,0)$ & $0(0,0)$ & $1(0,4)$ & $0(0,0)$ & $0(0,0)$ & & \\
\hline & All disorders & $1(0,4)$ & $5(2,1)$ & $0(0,0)$ & $1(0,4)$ & $0(0,0)$ & $1(0,4)$ & $0(0,0)$ & & \\
\hline & $\begin{array}{l}\text { Adaptive } \\
\text { Disorder } \\
\text { and/or } \\
\text { Anxiety }\end{array}$ & $2(0,8)$ & $7(2,9)$ & $0(0,0)$ & $0(0,0)$ & $1(0,4)$ & $3(1,2)$ & $2(0,8)$ & & \\
\hline & $\begin{array}{l}\text { Depressive } \\
\text { Disorder } \\
\text { Psychosis }\end{array}+$ & $0(0,0)$ & $0(0,0)$ & $0(0,0)$ & $1(0,4)$ & $0(0,0)$ & $0(0,0)$ & $0(0,0)$ & & \\
\hline & $\begin{array}{l}\text { Depressive } \\
\text { disorder } \\
\text { and/or } \\
\text { Anxiety }\end{array}$ & $6(2,5)$ & $\begin{array}{l}87 \\
(36,6)\end{array}$ & $3(1,2)$ & $11(4,5)$ & $9(3,7)$ & $\begin{array}{l}30 \\
(12,4)\end{array}$ & $7(2,9)$ & & \\
\hline & $\begin{array}{l}\text { Psychotic } \\
\text { Disorder }\end{array}$ & $0(0,0)$ & $5(2,1)$ & $0(0,0)$ & $6(2,5)$ & $1(0,4)$ & $2(0,8)$ & $3(1,2)$ & & \\
\hline
\end{tabular}

n: Marine diagnosed with PTSD. (\%) Percentage. NDR No data reported in the clinical profile.

An association was found between the psychological disorders, with the type of implemented psychotherapy, with a $\mathrm{p}$ value of $\leq 0.05$. The depressive and/or anxiety disorder was the prevailing among the patients and the psychotherapeutic techniques that were used in greater frequency were desensitization plus cognitive behavioral interventions in $49.6 \%$, followed by ocular movements reprocessing techniques in $3.3 \%$. For psychotic disorders, the desensitization technique was used in $2.5 \%$. Likewise, cognitive behavioral interventions, as well as desensitization techniques, were accompanied by medications such as antidepressants, among other mood and behavior modulators with a value of $\mathrm{p} \leq 0.05$. (See Table 4 ). 
Table 4. Type of psychotherapy applied according with the manifested psychological disorder by navy subjects

\begin{tabular}{|c|c|c|c|c|c|c|c|c|c|c|c|}
\hline & & \multicolumn{10}{|c|}{ Diagnosed Psychological Disorders } \\
\hline & & $\stackrel{z}{e}$ & 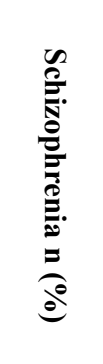 & 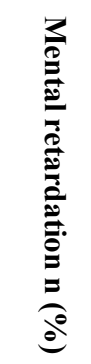 & 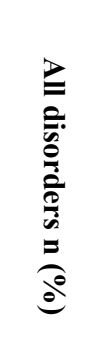 & 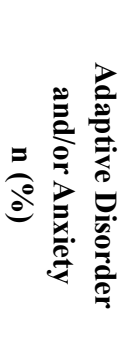 & 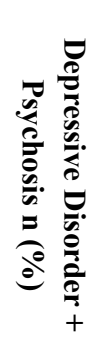 & 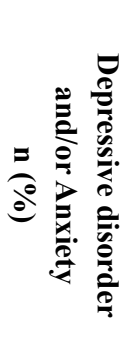 & 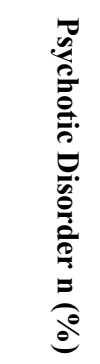 & $\mathbf{J i}^{2}$ & ప̃ \\
\hline \multirow{8}{*}{$\begin{array}{l}\text { Type of } \\
\text { Implemented } \\
\text { Psychotherapy }\end{array}$} & NRD & $30(12,4)$ & $2(0,8)$ & $0(0,0)$ & $1(0,4)$ & $3(1,2)$ & $0(0,0)$ & $21(8,7)$ & $8(3,3)$ & \multirow{8}{*}{135} & \multirow{8}{*}{0,00} \\
\hline & $\begin{array}{l}\text { Eye Movement } \\
\text { Reprocessing } \\
\text { Technique }\end{array}$ & $1(0,4)$ & $0(0,0)$ & $1(0,4)$ & $1(0,4)$ & $0(0,0)$ & $1(0,4)$ & $8(3,3)$ & $2(0,8)$ & & \\
\hline & $\begin{array}{l}\text { Isolation and } \\
\text { rest }\end{array}$ & $1(0,4)$ & $0(0,0)$ & $0(0,0)$ & $0(0,0)$ & $0(0,0)$ & $0(0,0)$ & $1(0,4)$ & $0(0,0)$ & & \\
\hline & $\begin{array}{l}\text { Cognitive } \\
\text { Behavioral } \\
\text { Interventions }\end{array}$ & $6(2,5)$ & $0(0,0)$ & $0(0,0)$ & $3(1,2)$ & $7(2,9)$ & $0(0,0)$ & $46(19)$ & $1(0,4)$ & & \\
\hline & Medicaments & $1(0,4)$ & $0(0,0)$ & $0(0,0)$ & $0(0,0)$ & $0(0,0)$ & $0(0,0)$ & $3(1,2)$ & $0(0,0)$ & & \\
\hline & $\begin{array}{l}\text { Ocular }+ \\
\text { Cognitive } \\
\text { Behavioral } \\
\text { Interventions }\end{array}$ & $0(0,0)$ & $0(0,0)$ & $0(0,0)$ & $0(0,0)$ & $1(0,4)$ & $0(0,0)$ & $0(0,0)$ & $0(0,0)$ & & \\
\hline & $\begin{array}{l}\text { Desensitization } \\
\text { Technique }\end{array}$ & $6(2,5)$ & $0(0,0)$ & $0(0,0)$ & $2(0,8)$ & $4(1,7)$ & $0(0,0)$ & $\begin{array}{l}47 \\
(19,4)\end{array}$ & $6(2,5)$ & & \\
\hline & $\begin{array}{l}\text { Desensitization } \\
\text { Technique }+ \\
\text { Cognitive } \\
\text { Behavioral } \\
\text { Interventions }\end{array}$ & $0(0,0)$ & $0(0,0)$ & $0(0,0)$ & $1(0,4)$ & $0(0,0)$ & $0(0,0)$ & $\begin{array}{l}27 \\
(11,2)\end{array}$ & $0(0,0)$ & & \\
\hline
\end{tabular}

n: Marine diagnosed with PTSD. (\%) Percentage. NDR No data reported in the clinical profile.

An associative approach was found with a $p$ value of $\leq 0.05$ between the type of implemented psychotherapy and the received psychopharmacological treatment with the mixture of some type of drug. The desensitization technique with $16.5 \%$ associated with the use of antidepressants, followed by the use of antidepressants with cognitive behavioral intervention in $12.4 \%$. (Table 5). 
Table 5. Use of psychopharmacological treatment with the type of implemented psychotherapy in military navy personnel with diagnosis of PTSD

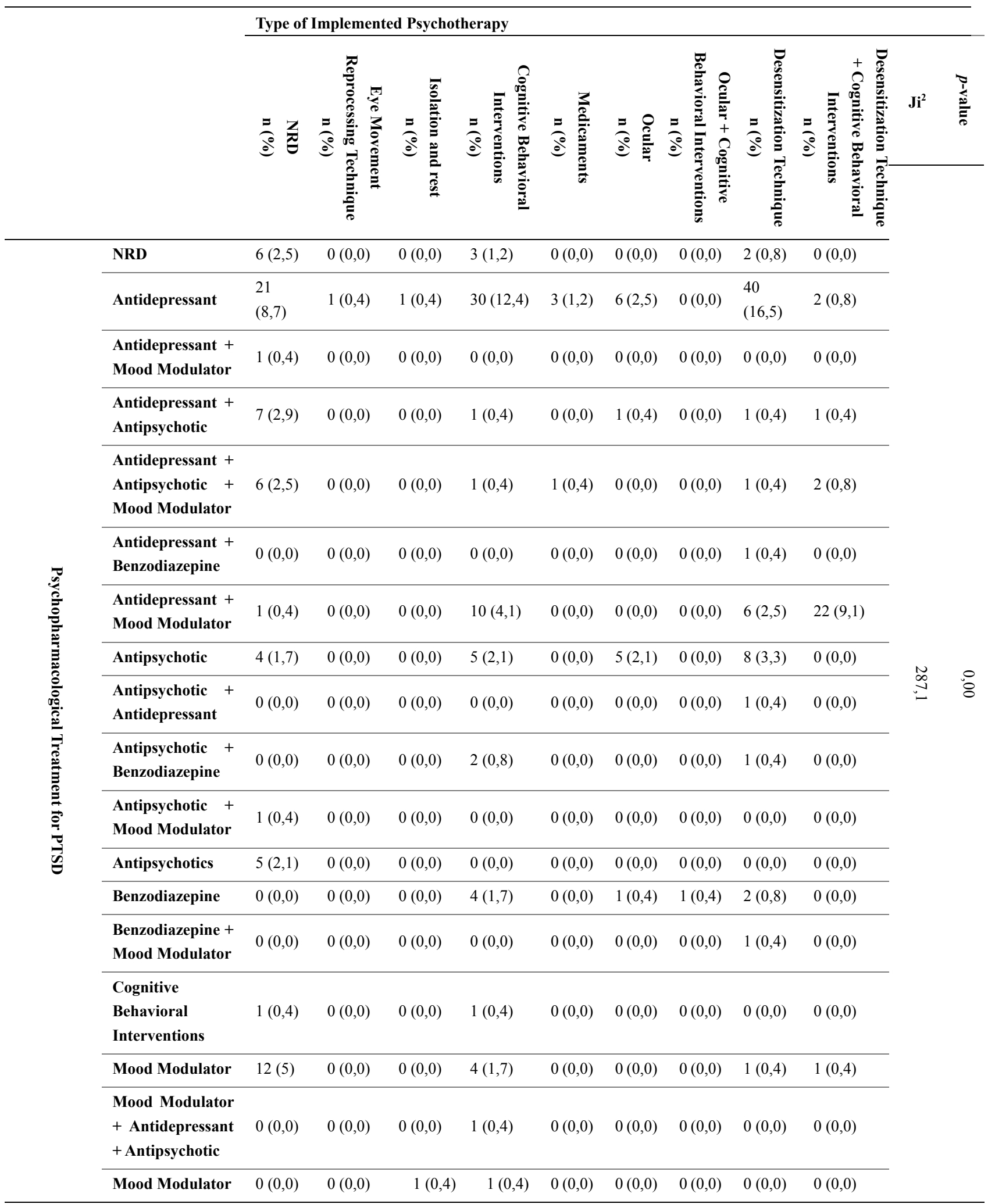

n: Marine diagnosed with PTSD. (\%) Percentage. NDR No data reported in the clinical profile. 


\section{Discussion}

In our study it was evidenced that the subject can be the victim of a traumatic event or to find out through a third party (Trickey et al., 2012; Van der Kolk, 2000).

Patients with PTSD, consult the doctor for difficulty sleeping, lack of concentration, feeling overly alert or easily frightened, fits of anger, etc. (Van der Kolk, 2000).

Psychoactive substances consumption may be due to the traumatic event causing a demand to the organism (Trickey et al., 2012), which means, the abuse consumption of psychoactive substance, is a self-therapy for PTSD symptomatology (Carvajal, 2002).

Marines with PTSD who are married tend to have violent homes, situation that is often hidden (Medina-Mora et al., 2005).

Our findings showed that $47.9 \%$ of the military subjects were diagnosed with some kind of trauma during childhood due to physical and psychological abuse. Brewin, compared a group of civilian population with war veterans, finding risk factors classified into three categories: the first group is sex, age of trauma, and race. The second group consists of educational level, previous trauma and adverse biography in childhood, where the sum of these factors predicts PTSD more consistently, but may vary according to the studied population and the methods used for diagnosis. A third group of predictive effects, such as: personal psychiatric history, history of childhood abuse and family history of mental disorders (Trickey et al., 2012).

PTSD treatment now involves a multidimensional variety of modalities where pharmacological, psychosocial resources are applied (Odriozola \& de Corral Gargallo, 1997). Cognitive-behavioral techniques are the most used, especially in more advanced stages of the disorder, the most traditional is the systematic desensitization to implosive techniques using procedures such as "stress inoculation" and exposure (thoughts, imagery, photographs and films) $(13,19)$, or even the technique of desensitization by means of eye movements (Shapiro, 1989), the reported levels of success in the short and medium term are in some cases comparable and even better than those of pharmacotherapy (Carvajal, 2002), These data are congruent with the techniques used by health personnel, where the most used psychotherapy was cognitive-behavioral treatment, followed by desensitization.

\section{Conclusion}

The study provides elements of assessment for early identification of posttraumatic stress disorder in military personnel exposed to traumatic actions.

We consider that there is no specific number of combats to present the PTSD, since it depends more on the maturity of the people, type of military training received and whether or not there are previous traumas, even existence of genetic susceptibility.

The treatment received is adjusted with the psychiatric protocols according to the type of psychological disorder.

\section{Competing Interests Statement}

The authors declare that they have no competing or potential conflicts of interest.

\section{References}

Carvajal, C. (2002). Trastorno por estrés postraumático: aspectos clínicos. Revista chilena de neuro-psiquiatría, 40, 20-34. https://doi.org/10.4067/S0717-92272002000600003

Castaño, L. C., \& Rosado, A. M. O. (2015). Estilos de personalidad y estrategias de afrontamiento al estrés en soldados: un estudio correlacional. Revista de Psicología Universidad de Antioquia, 7(1), 35-56.

Corzo, P., \& Bohórquez, A. P. (2009). Prevalencia del trastorno por estrés agudo y trastorno por estrés postraumático en soldados colombianos heridos en combate. Rev Fac Med, 17(1), 14-19.

Fink, D. S., Cohen, G. H., Sampson, L. A., Gifford, R. K., Fullerton, C. S., Ursano, R. J., \& Galea, S. (2016). Incidence of and risk for post-traumatic stress disorder and depression in a representative sample of US Reserve and National Guard. Annals of epidemiology, 26(3), 189-197. https://doi.org/10.1016/j.annepidem.2016.01.003

Friedman, M. J., Schnurr, P. P., \& McDonagh-Coyle, A. (1994). Post-traumatic stress disorder in the military veteran. The Psychiatric clinics of North America, 17(2), 265.

Loaiza, O., \& Posada, J. L. (2016). Psicología militar: Conceptualización e investigaciones contemporáneas. PSIENCIA. Revista Latinoamericana de Ciencia Psicológica, 8(2). Retrieved from http://www.psiencia.org/ojs/index.php/psiencia/article/view/198 
Medina-Mora, M. E., Borges-Guimaraes, G., Lara, C., Ramos-Lira, L., Zambrano, J., \& Fleiz-Bautista, C. (2005). Prevalencia de sucesos violentos y de trastorno por estrés postraumático en la población mexicana. Salud Pública de México, 47(1), 8-21. https://doi.org/10.1590/S0036-36342005000100004

Mitchell, K. S., Porter, B., Boyko, E. J., \& Field, A. E. (2016). Longitudinal Associations Among Posttraumatic Stress Disorder, Disordered Eating, and Weight Gain in Military Men and Women. American journal of epidemiology, kwv291. https://doi.org/10.1093/aje/kwv291

Odriozola, E. E., \& de Corral Gargallo, P. (1997). Avances en el tratamiento cognitivo-conductual del trastorno de estrés postraumático. Ansiedad y estrés, 3(2), 249-264.

Shapiro, F. (1989). Eye movement desensitization: A new treatment for post-traumatic stress disorder. Journal of behavior therapy and experimental psychiatry, 211-217. https://doi.org/10.1016/0005-7916(89)90025-6

Stein, M. B., Jang, K. L., Taylor, S., Vernon, P. A., \& Livesley, W. J. (2002). Genetic and environmental influences on trauma exposure and posttraumatic stress disorder symptoms: A twin study. American Journal of Psychiatry, 159(10), 1675-1681. https://doi.org/10.1176/appi.ajp.159.10.1675

Suárez, C. L. R., \& Peralta, A. J. O. (2016). Los militares y policías como seres humanos en medio del conflicto armado. Escuela de Derechos Humanos y Derecho Internacional Humanitario, 85.

Trickey, D., Siddaway, A. P., Meiser-Stedman, R., Serpell, L., \& Field, A. P. (2012). A meta-analysis of risk factors for post-traumatic stress disorder in children and adolescents. Clinical psychology review, 32(2), 122-138. https://doi.org/10.1016/j.cpr.2011.12.001

Ursano, R. J., Kao, T., \& Fullerton, C. S. (1992). Posttraumatic stress disorder and meaning: structuring human chaos. The Journal of nervous and mental disease, 180(12), 756-759. https://doi.org/10.1097/00005053-199212000-00003

Vallejo Samudio, Á. R., \& Terranova Zapata, L. M. (2009). Estrés postraumático y psicoterapia de grupo en militares. Terapia psicológica, 27(1), 103-112. https://doi.org/10.4067/S0718-48082009000100010

Van der Kolk, B. (2000). Posttraumatic stress disorder and the nature of trauma. Dialogues in clinical neuroscience, $2(1), 7$.

\section{Copyrights}

Copyright for this article is retained by the author(s), with first publication rights granted to the journal.

This is an open-access article distributed under the terms and conditions of the Creative Commons Attribution license (http://creativecommons.org/licenses/by/4.0/). 